\title{
Characteristic accumulation and soil penetration of polychlorinated biphenyls and polybrominated diphenyl ethers in wastewater irrigated farmlands
}

\author{
Thanh Wang, Yawei Wang, Jianjie Fu, Pu Wang, Yingming Li, Qinghua Zhang, Guibin Jiang* \\ State Key Laboratory of Environmental Chemistry and Ecotoxicology, Research Center for Eco-Environmental Sciences, Chinese Academy of Sciences, \\ P.O. Box 2871, Beijing 100085, China
}

\section{A R T I C L E I N F O}

\section{Article history:}

Received 4 May 2010

Received in revised form 29 June 2010

Accepted 18 July 2010

Available online 16 September 2010

\section{Keywords:}

PCBs

PBDEs

Wastewater irrigation

Farm soil

\begin{abstract}
A B S T R A C T
The impact of wastewater irrigation on the distribution of two groups of persistent organic pollutants (POPs), polychlorinated biphenyls (PCBs) and polybrominated diphenyl ethers (PBDEs), in farm soil was investigated in this study. The concentrations of total analyzed PCBs were in the range 256$2140 \mathrm{pg} \mathrm{g}^{-1}$ on dry weight basis in surface soils. There was a higher accumulation of PCBs in farms irrigated by wastewater, with decachlorobiphenyl (CB-209) as the predominant congener. The spatial distributions of PBDEs were similar although not as obvious as that of PCBs, and BDE-209 was the predominant congener at 2040-496 $000 \mathrm{pg} \mathrm{g}^{-1} \mathrm{dw}$, accounting for $>96 \%$ of the total analyzed PBDEs. However, no significant correlations could be found between PCB and PBDE concentrations in the topsoil samples, and also with soil organic content between the different sites. On the other hand, soil vertical profiles showed significant relationship with soil organic content in cores taken from farms irrigated with wastewater. The vertical distribution was quite uniform at the topsoil, corresponding to the plowed layer, and decreased thereafter exponentially. Furthermore, the soil vertical distribution was found to be congener specific for PCBs, where less chlorinated congeners were able to penetrate deeper into the soil while heavier congeners were more restricted in their movement. This fractionation process was however not found for PBDEs. Also, the prevalence and high relative concentrations of CB-11 and CB-209 suggests that these PCB congeners should more often be included in routine environmental analysis in order to identifying unusual contamination sources.
\end{abstract}

(c) 2010 Elsevier Ltd. All rights reserved.

\section{Introduction}

Persistent organic pollutants (POPs) have been of great environmental and human health concerns for several decades. These pollutants are persistent in the environment, can travel over long distances, able to bioaccumulate through the food web and are toxic. Polychlorinated biphenyls (PCBs) are a group of POPs that theoretically consists of 209 congeners, and has been targeted by the Stockholm Convention on Persistent Organic Pollutants for final elimination. A structural similar group of compounds, polybrominated diphenyl ethers (PBDEs), have been used in large quantities as flame retardants in upholstery and electronics. Due to increasing levels in the environment and wildlife, two technical formulations (penta and octa commercial mixtures) of PBDEs have recently been listed into the Stockholm Convention for prohibition of production and usage. Despite intensive research, there are still deficiencies in the understanding of the environmental fate of these POPs. For example, the extent and significance of the soil compartment to act as a repository or sink to the global cycling

\footnotetext{
* Corresponding author. Tel.: +86 106284 9179; fax: +86 1062849334

E-mail address: gbjiang@rcees.ac.cn (G. Jiang).
}

of POPs is still not fully understood (Meijier et al., 2003; Ockenden et al., 2003). Many previous studies focus on the role of soil in forests or grasslands, which have been found to be able to retain large amounts of POPs (Ockenden et al., 2003; Moeckel et al., 2008). In farmlands, POPs that are not intended as pesticides usually enter the soil compartment through atmospheric deposition or unintentionally through contaminated biosolids or irrigation sources (Alcock et al., 1996; Chen et al., 2005). Several previous studies have detected PCBs and PBDEs in municipal treatment plants (North, 2004; Guo et al., 2009), and it has also been found that spray field irrigation of treated municipal wastewater can be potential atmospheric sources of PBDEs to the surrounding region (Goel et al., 2006). Due to factors such as limited water supply, high nutrition load and economic reasons, some farmers in peri-urban regions utilize untreated or partially treated wastewater from contaminated rivers to irrigate their farmlands. Crude estimations imply that the area under wastewater irrigation might reach as high as 20 million hectares globally, with a major part occurring at peri-urban regions in developing countries (Scott et al., 2004). The proximity to urban and industrial areas can therefore lead to contamination of certain chemicals and pathogens to these irrigation sources which further can be transferred to farm soils, crops 
and eventually to humans. Since urban areas have been considered as contemporary sources of POPs to the environment, it is important to assess the potential transfer of POPs to farm soils in peri-urban farmlands.

This paper examines and compares the distribution of legacy POPs (PCBs) with that of the currently used PBDEs in agricultural soils at an urban-rural fringe in order to discern potential contamination by wastewater irrigation. We are also interested in comparing the downward movements of these two POPs in farm soils since previous reports mainly focus on the distribution of PCBs at the plowed surface layer (During and Gath, 2002; Armitage et al., 2006) or the effect of biosolids and sewage sludge amendment (Beck et al., 1996; Wilson et al., 1996; Matscheko et al., 2002). Also, few field studies have been instigated to assess the vertical distribution of emerging POPs such as PBDEs in wastewater irrigated farms. It is hoped that the results from this study will provide useful information on the transfer of these POPs from wastewater irrigation sources to farms and their distribution in agricultural soil.

\section{Method section}

The Tongzhou district (TZ) is located in southeast Beijing and situates both industrial and agricultural activities (Fig. SI-1). The Liangshui river (LSR) flows through the district and is utilized as a recipient for wastewater from both treated/untreated industrial and local municipal wastes through a complex network of smaller connecting streams and ditches. Besides from these, the LSR also receives treated effluents from a large wastewater treatment plant (WWTP) located around $15 \mathrm{~km}$ north of the river. The predominant soil types in this area are loamy soils, and winter wheat and summer maize is the main crop rotation practice. The farms at the main sampling sites were categorized as wastewater irrigated only ( $\mathrm{S}$ sites), or mixed irrigated ( $M$ sites) which is defined as farms that have been irrigated with both groundwater and wastewater at some point in recent time. The wastewater sources at $\mathrm{M}$ sites do not necessarily come directly from the LSR but could also be from local municipal and industrial wastewater effluents. Additional soil samples were collected from farm plots irrigated solely by groundwater ( $G$ sites). Samples were also collected at a grass lawn at the north of urban Beijing (site R) in order to distinguish potential urban-rural differences. Surface soils $(0-20 \mathrm{~cm})$ were collected as composite samples during three sampling campaigns; July (site M1, M3, S3, R) and November 2008 (M1, M2, M4, S5, G) and May 2009 (M1, S1, S2, S4, S6, S7, S8) (Fig. 1).Vertical soil profiles were collected using in-house built steel core probes ( $1 \mathrm{~m}$ in length and $15 \mathrm{~cm}$ in diameter) at penetration depths of approximately $70 \mathrm{~cm}(\mathrm{M} 2, \mathrm{~S} 2, \mathrm{~S} 3, \mathrm{~S} 6, \mathrm{R})$. The core samples were sectioned into $2-4 \mathrm{~cm}$ layers in order to obtain high vertical resolution. Water samples (W0, W1, W2) were collected from the LSR at a depth of approximately $20 \mathrm{~cm}$ below surface using amber glass bottles pre-cleaned with hexane.

Qualitative and quantitative determination of target analytes was based on an established isotope dilution method, and has been described in our previous works (Wang et al., 2007). The PCB congeners reported in this study include 12 dioxin-like (DL) PCBs (CB$77,81,105,114,118,123,126,156,157,167,169$ and 189), six indicator congeners (CB-28, 52, 101, 138, 153, and 180), and eight other congeners (CB-3, 11, 15, 19, 202, 205, 208, and 209). Separate analysis was also performed for 14 PBDE congeners (BDE-17, 28, 47, 66, 71, 85, 99, 100, 138, 153, 154, 183, 190 and 209). All soil samples were reported on a dry weight ( $\mathrm{dw}$ ) and blank corrected basis unless otherwise mentioned.

Detailed information on the sampling sites, extraction, analysis and QA/QC can be found in Supplementary Material.

\section{Results and discussion}

\subsection{Spatial distribution and congener composition of PCBS and PBDEs}

Numerous studies have been carried out in order to investigate the contamination of PCBs and PBDEs in agricultural soils due to

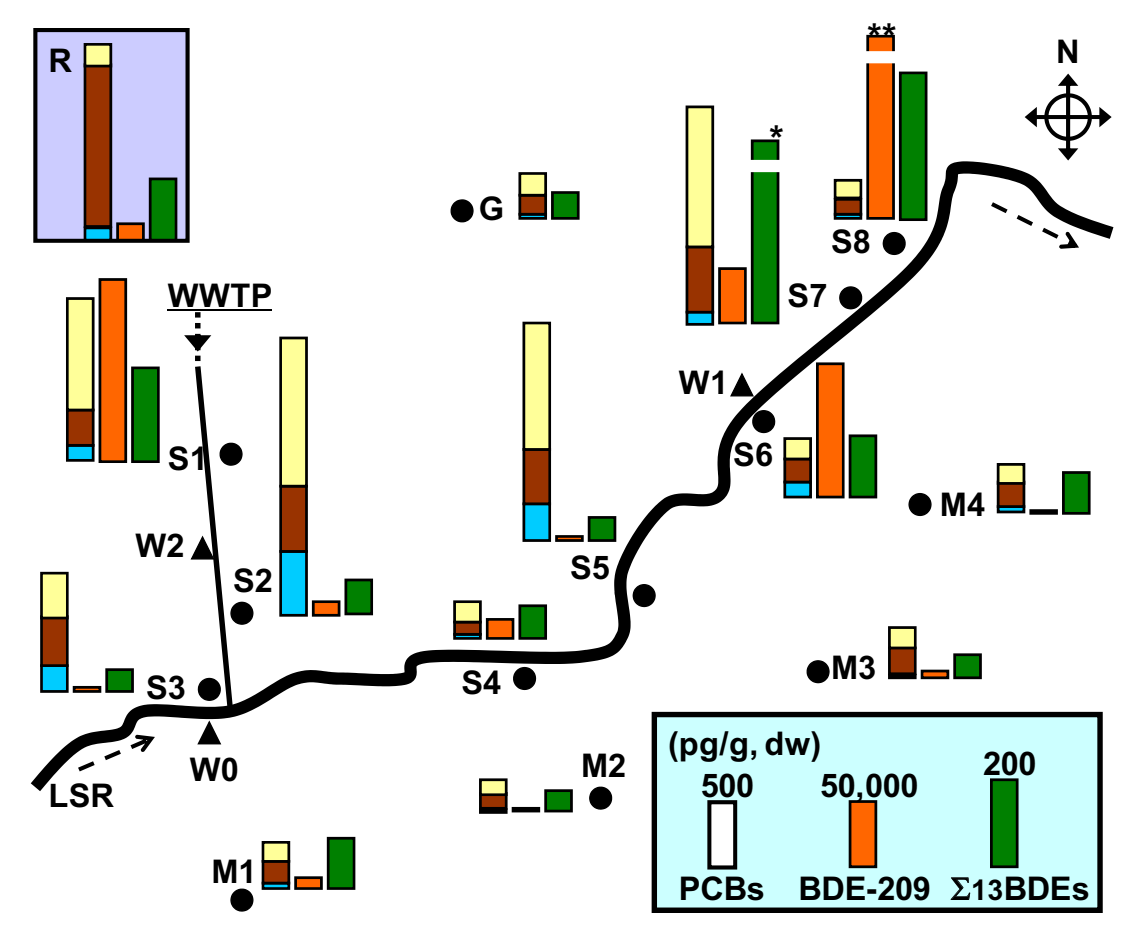

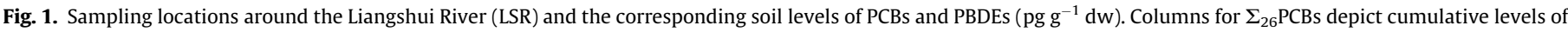

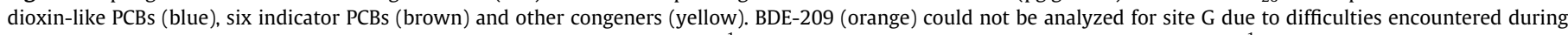

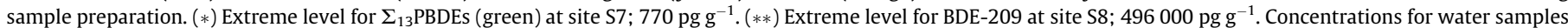

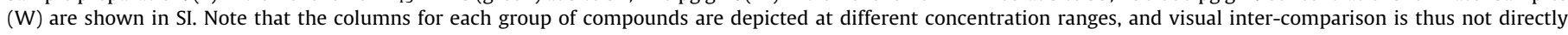
feasible. (For interpretation of the references to colour in this figure legend, the reader is referred to the web version of this article.) 
amendment of biosolids and sewage sludge (Beck et al., 1996; Matscheko et al., 2002; Sellstrom et al., 2005; Armitage et al., 2006), but few have investigated the accumulation of these chemicals as effect of wastewater irrigation. Concentrations of individual PCB and PBDE congeners at each sites are shown in Supplementary Material (Table SI-3), and the total levels are illustrated in Fig. 1. The $\Sigma_{26} \mathrm{PCBs}$ in topsoils ranged between 256 and $2140 \mathrm{pg} \mathrm{g}^{-1} \mathrm{dw}$ in the TZ area, and averaged $1480 \mathrm{pg} \mathrm{g}^{-1} \mathrm{dw}$ at the urban site (R). As can be seen, there is a noticeable spatial trend for PCBs with higher levels at those farm fields closest to the LSR (sites S). This similar trend was also found by Chen et al. (2005) for soil PAHs in the same region. However, the extent of PCBs contamination can only be considered as moderate compared to background levels in developed countries and highly contaminated areas such as e-waste recycling regions (Meijier et al., 2003; Wong et al., 2007). The PCB congener distribution differs among the specific sites; the urban site $(\mathrm{R})$ is predominated by the six indicator congeners ( $>80 \%$ ) and with highest concentrations for CB-138, 153,180 and 28 . This congener pattern is comparable to that in typical Chinese urban soils (Ren et al., 2007). An exception is that the relative contribution of hepta-CBs was higher than trichlorinated congeners in our study (Fig. 2a), which might be attributed to the use of reclaimed wastewater in this studied urban site. Irrigation by reclaimed wastewater is a common practice due to enduring shortage of water in the northern region of China. Farms in TZ that are more distant from the main channel of LSR (sites M and G) had roughly equal contribution of indicator and "other" PCB congeners. Lower molecular weight (mono- to tetrachlorinated) congeners contributed to almost $60 \%$ of the reported PCB congeners in these sites. The results also indicate an urban-rural fractionation effect with heavier congeners dominating the urban area whereas the relatively more mobile lower chlorinated PCBs are abundant in rural soils (Harner et al., 2004). However, wastewater irrigated farms showed a different pattern with elevated levels of heavier congeners, in particular decachlorobiphenyl (CB-209, Fig. 2a). The average concentration of CB-209 in wastewater irrigated fields near the river ( $\mathrm{S}$ sites) was $413 \mathrm{pg} \mathrm{g}^{-1} \mathrm{dw}$ which accounted for around $37 \%$ of the $\Sigma_{26}$ PCBs. Results from previous studies suggest that elevated levels of CB-209 in wastewater treatment plants might be of industrial origin, although it is presently unclear what these industries are (Song et al., 2006; Guo et al., 2009. The
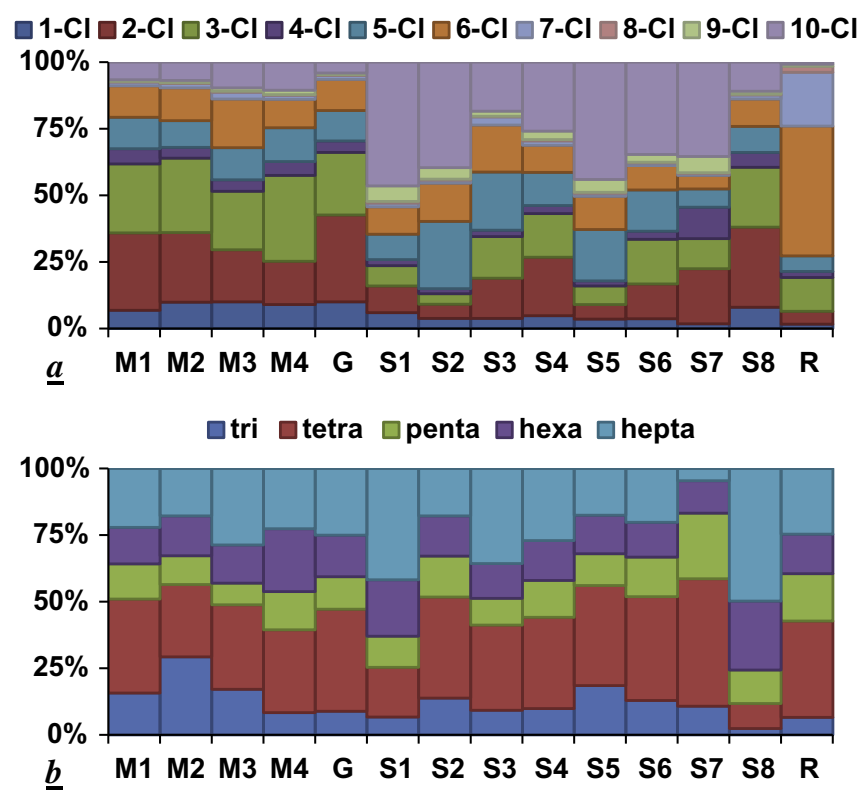

Fig. 2. Site specific homolog profiles for: (a) PCBs (mono-deca), and (b) PBDEs (trihepta, excl. BDE-209).
$\Sigma_{26}$ PCBs levels from the LSR in our study varied between 550 and $1240 \mathrm{pg} \mathrm{L}^{-1}$ (Table SI-11) with significantly higher levels at the channel which receives treated effluent discharge from the WWTP (site W2), further implying that the WWTP is likely to be a significant source for the elevated soil PCB levels in the wastewater irrigated fields.

Soil PBDE levels also seem to be higher around the LSR although the general pattern was not as apparent as that for PCBs. BDE-209 was the predominating congener and varied between 2040 and $496.000 \mathrm{pg} \mathrm{g}^{-1} \mathrm{dw}$, accounting for $>96 \%$ of the total PBDEs. This corresponds well with the fact that deca-BDE is the main technical PBDE mixture used in China. The BDE-209 levels at the S-sites averaged at $102 \mathrm{ng} \mathrm{g}^{-1} \mathrm{dw}$ and were significantly higher than those levels reported by Zou et al. (2007) in agricultural soils in southern China. Water concentrations of PBDEs in our study were several times higher than that for PCBs (Table SI-11), reflecting the current trend of higher environmental input for PBDEs. The water samples were also dominated by BDE-209, accounting for almost $90 \%$ of the total PBDEs, and the levels were also highest at the discharge channel (W2). The most extreme BDE-209 levels in our sites were comparable to those soils that were amended by sewage sludge in Europe (Sellstrom et al., 2005; Ejarrat et al., 2008). It can therefore not be excluded that some of these fields might also have been amended by sewage sludge, although other local sources could also contribute to the elevated levels. There was a moderate but very significant correlation between BDE-209 and $\Sigma_{13}$ PBDEs among the sites in our study $\left(R^{2}=0.54, p<0.01\right)$. The spatial homolog patterns for $\Sigma_{13}$ PBDEs (excl. BDE-209) were quite consistent although two sites (S1, S8) showed slight deviation with higher brominated congeners dominating (Fig. 2b). A study by Sun and coworkers did not find significantly different PBDE levels between wastewater irrigated farm soils to those that uses other irrigation methods in a region east from our sampling sites (Sun et al., 2009). The PBDE concentrations (excl. BDE-209), were between 28.2 and $228 \mathrm{pg} \mathrm{g}^{-1} \mathrm{dw}$ in their study and were at the same range as reported here, but the levels of BDE-209 were several times lower (456-3150 $\left.\mathrm{pg} \mathrm{g}^{-1} \mathrm{dw}\right)$. This further implicates that local sources exist in this area, and support the general assumption that the mobility of BDE-209 can be quite restricted once released into the environment.

There was no significant inter-correlation between PCBs and PBDEs in the topsoil samples, and the spatial distributions of soil organic carbon (SOC) content was also not significantly correlated with either PCBs or PBDEs.

\subsection{Seasonal variability}

A possible explanation for the spatial variation in soil levels is the different time period of the sampling occasions. Input of PCBs and PBDEs from discrete irrigation episodes and variation in environmental conditions such as temperature and wet/dry deposition can have large influence on the soil levels. To assess the potential impact of seasonal variability in this region, we consistently sampled site M1 through all three campaigns. Highest concentration of BDE-209 was found in May (11500 $\mathrm{pg} \mathrm{g}^{-1} \mathrm{dw}$ ) which was 1.4 and 3 times higher than in July and November, respectively (Table SI2 ), and a similar trend was also found for $\Sigma_{13}$ PBDEs. Such large seasonal variation was however not found for PCBs (ranging 308$385 \mathrm{pg} \mathrm{g}^{-1} \mathrm{dw}$ ). This site has not been irrigated by wastewater in recent years, and the different trends might be due to change in irrigation practice, application of sewage sludge and current lower environmental input of PCBs. Another probable explanation is the relatively unstable nature of PBDEs compared to PCBs, in particular BDE-209 which is known to debrominate under photolytic (Soderstrom et al., 2003) and anaerobic conditions (Gerecke et al., 
2005). This might also explain the somewhat inconsistent spatial trends of BDE-209 in our study.

\subsection{Vertical distribution of PCBs and PBDEs in agricultural soils}

In undisturbed soils, the concentrations of POPs often decrease in an exponential trend below the air-soil interface (Hollander et al., 2007). The concentrations shown in Fig. 3 were quite uniform for $\Sigma_{26} \mathrm{PCBs}$ and $\Sigma_{13} \mathrm{PBDEs}$ along the topsoil profile until a depth of $20-30 \mathrm{~cm}$, corresponding to the typical plowing depth in agricultural soils. The large variability of BDE-209 in topsoil might be due to its strong adsorption to organic matter which strongly restricts its movement in soil, and the relatively rapid degradation. The concentrations at the subsurface soils (below $20-30 \mathrm{~cm}$ ) showed a decreasing tendency and were congener specific for PCBs; lower chlorinated congeners such as CB-11 and CB-28 were able to penetrate deeper whereas the concentrations of heavier congeners such as CB-209 declined very rapidly along the subsoil profile (Fig. 4, Figs. SI-2, SI-3, and SI-5). A similar trend was found in contaminated paddy soils in southern China (Bi et al., 2002). Several studies found that leaching of PCBs through the soil column should not be significant due to their relatively low water sol- ubilities and large Kow values (Cousins et al., 1999; Doick et al., 2005). However, other studies on soil surface profiles in forest and montane areas suggest that leaching of PCBs can occur, mostly in association with DOM (Krauss et al., 2000; Moeckel et al., 2008). In our study, an increasing relative amount of lower chlorinated congeners with depth below the plowed surface suggests selective transport of PCBs in agricultural soils (Fig. 4). This might be attributed to the soil properties and irrigation practices in our study sites, and that the comparisons made in our work included congeners of all chlorinated levels (mono to deca) which cover a wide range of water solubilities and Kow values ( $\log 4.6-8.2)$. In addition, by comparing the homolog profile of water samples with that of the soil profiles, it can further be perceived that mono- to trichlorinated congers move through the soil relatively unretained, whereas higher chlorinated congeners accumulated at the plowed surface (Fig. 4).

To further investigate the extent of change in $P C B$ composition with soil depth, the shift $(S)$ was calculated by the following equations modified from Moeckel et al. (2008):

$$
R_{L}=\frac{C_{P C B-i}}{C_{P C B-209}}
$$
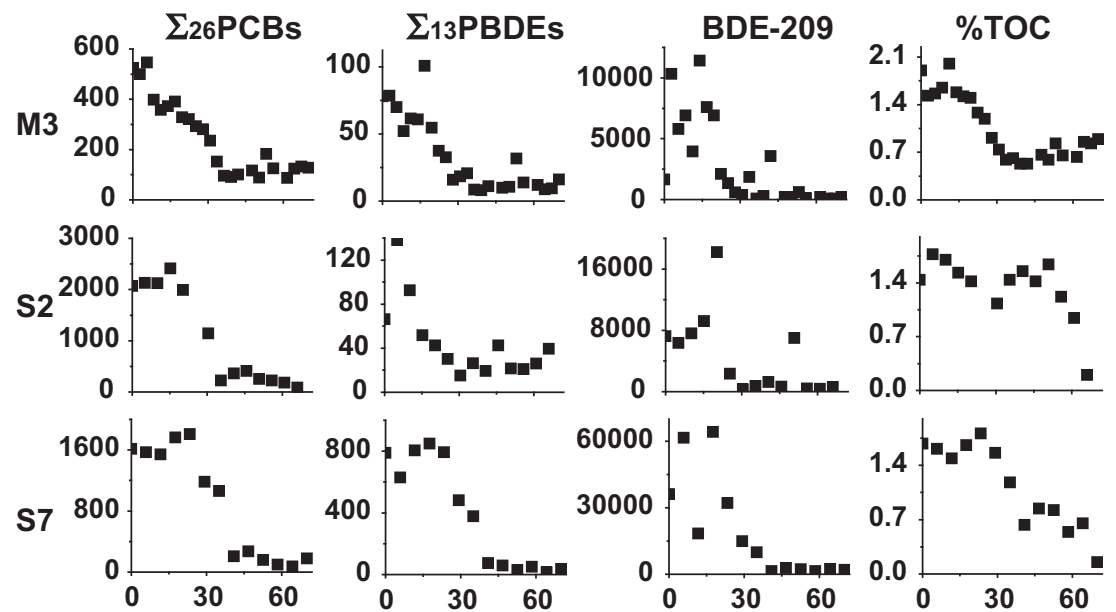

Fig. 3. Vertical soil profiles for $\Sigma_{26} \mathrm{PCBs}$, PBDEs and percent organic carbon from three soil cores. Scale of $y$-axis in pg g ${ }^{-1} \mathrm{dw}$, and $x$-axis in cm below soil surface.
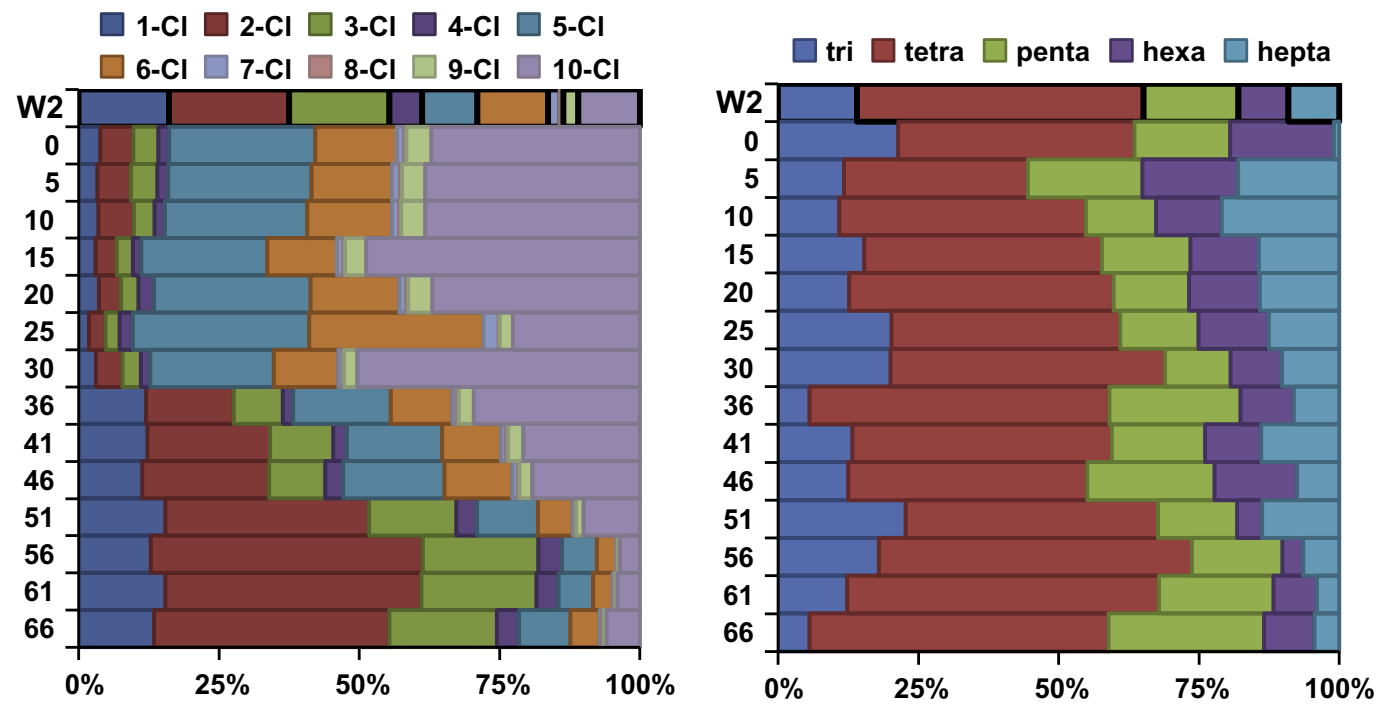

Fig. 4. Homolog profile for $\Sigma_{26}$ PCBs (left) and $\Sigma_{13}$ PBDEs (right) for each layer in soil core S2 (in cm below surface) and water sample (W2). 
$S_{L 12}=\frac{R_{L 2}}{R_{L 1}}$

where $R$ is the ratio of the concentration of an individual congener $(P C B-i)$ divided by that of CB-209 at a specific soil layer $(L)$. The shift ( $S$ ) is the ratio of $R$ values between a layer (L2) and the direct overlaying soil layer ( $L 1)$. The selection of CB-209 as the normalizing congener is mainly due to its high Kow, slow degradation, and low volatility and water solubility. The $S$-values allows for estimating the vertical movements of each congener in comparison to that of CB-209 and are independent of the different concentration ranges ( $S$-value for CB-209 is equal to 1 ). Fig. 5 depicts the change of $S$-values along the soil profile with the Kow values of selected PCB congeners. As expected, the shifts in composition were quite consistent throughout the plowed surface layers at sites S2 and S7, after which the congener fractionation becomes more apparent within a depth range of $\sim 10 \mathrm{~cm}$. This process was most prominent for PCB congeners with $\log$ Kow values below 5.5 (the $\log$ Kow for CB-28). For site M3, the fractionation range was even narrower ( $\sim 5 \mathrm{~cm}$, Fig. SI-7). The combination of comparatively lower Kow values and higher water solubilities should facilitate leaching of these lower chlorinated congeners. Results from Moeckel et al. (2008) showed that PCBs in soil profiles in forest areas also did not show Kow dependence for congeners with $\log$ Kow above $~ 6.3$. The difference in the Kow cutoff values of about one order of magnitude might be due to different soil types, properties and agricultural practices. The results indicate that a higher relative amount of lower chlorinated PCB congeners might be available for root uptake at the subsurface layers. However, the extent of plant-root uptake would depend on the specific congener and the bioavailable fraction.

For PBDEs, the concentrations decreased with depth similar to that for PCBs (Fig. 3). In contrast to PCBs, very limited studies have been conducted to investigate the vertical distribution of PBDEs in soil. Zou et al. (2007) found a general decrease in PBDE levels with depth in farm soils with a fairly uniform composition pattern. This trend was also observed in our study with a consistent homolog profile for $\Sigma_{13}$ PBDEs throughout the soil profiles, suggesting nonselective vertical movement (Fig. 4). The reason for this discrepancy is currently unclear but might be due the higher relative hydrophobicities of PBDEs or that these compounds have not yet reached steady state in the environment. The lowest brominated PBDE congener analyzed in our study, BDE-17, has a $\log$ Kow of around 5.7, which is slightly higher than the cutoff limit found for PCBs (Fig. 5). Furthermore, many BDE congeners at the lower layers of the soil cores were close or below the method limit of quantification and thus the reliability of their concentration trends cannot be fully ensured.

Site S3 is situated at a former industrial area on which temporary farm plots recently have been arbitrarily set up, and also shows decreasing trends although not as apparent as for the other cores from TZ (Fig. SI-4). The soil core from the urban site (R) did not show any clear trend along the depth profile. This might be attributed to the fact that this area has undergone construction in recent decades and thus the soil structure would have been severely disturbed. This can be seen in the disparity in TOC along the soil profile (Fig. SI-6). In our study, the organic carbon contents were significantly correlated with the concentrations of the soil cores except for site R and S3, suggesting that the retention capacity in most of the farm soils has not been exceeded. The R-squared values $(p<0.05)$ for log concentrations against \%TOC were around 0.3 for both $\Sigma_{26} \mathrm{PCBs}$ and $\Sigma_{13} \mathrm{PBDEs}$ in soil core S2, and around 0.8 for both soil core M3 and S7. This indicates that the soil organic carbon is a major factor governing the vertical movement of the two groups of POPs in these agricultural sites. Furthermore, as the change of $\mathrm{PCB}$ congener compositions occurred in conjunction with the dramatic change of \%TOC, one can also infer that soil organic matter has a large influence on the congener fractionation of PCBs. However, dissolved organic matter from the water source might also enhance the mobility of higher molecular weight POPs (e.g. CB-209 and BDE-209) into deeper soil horizons than otherwise expected (Beck et al., 1996; ter Laak et al., 2009).

\subsection{The presence of $C B-11$ and $C B-209$ in agricultural soils}

Both CB-209 and CB-11 are usually low priority congeners since they are not found in any significant amounts in common technical PCB mixtures. Although this and previous studies have found that WWTPs which processes industrial wastes can be a major source of CB-209, there is still uncertainty about the origin of the specific industrial source(s) (Guo et al., 2009). This fully chlorinated congener has been intermittently found in the environment; Howell and coworkers found relatively high levels of CB-209 in water and sediment in the Houston Shipping Channel which has a large petrochemical industry (Howell et al., 2008). High relative abundance
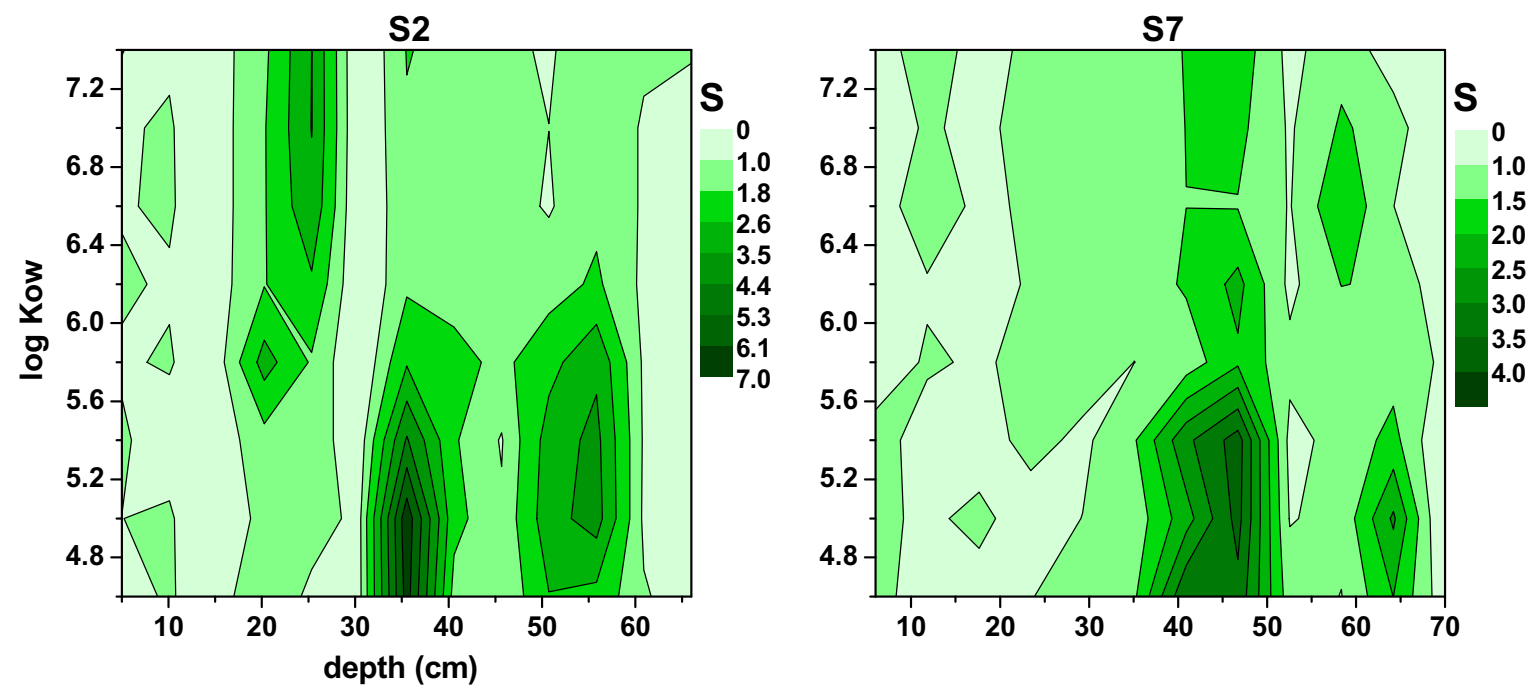

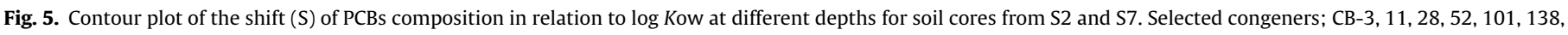
$153,180$. 
of CB-209 (up to 20\%) was also found in the Delaware River which was suspected to be originated from a titanium dioxide purification plant (Rowe et al., 2007). Also, some specific paint pigments were found to contain high amounts of both CB-11 and CB-209 (Hu and Hornbuckle, 2010), and thus pigment industries could also be a potential source to the WWTP and the Liangshui River in our study region. Although CB-209 is considered not to be particularly toxic (Han et al., 2009), the presence of high levels of CB-209 should be cautioned since it may eventually be degraded to more toxic lower chlorinated congeners in the environment. For CB-11, recent studies suggest that it is ubiquitous in the atmosphere, and sources such as degradation of higher chlorinated congeners and release from municipal solid waste incineration plants have been proposed (Rodenburg et al., 2010). Due to its high vapor pressure, it should mainly exist in the ambient environment in gasphase. We found here in our study that the levels of CB-11 in soil were at a similar range to that of $\mathrm{CB}-28$, and were only slightly higher at the wastewater irrigated sites. However, the water levels were higher at the W2 site which implies that, in addition to atmospheric deposition, the WWTP could also be a potential source of CB-11.

\section{Conclusions}

This study shows that irrigation of farmlands from contaminated rivers can result in accumulation of certain PCBs and PBDEs. Furthermore, it is suggested that the use of indicator PCBs is not always informative in certain situations and that decachlorobiphenyl, and also CB-11, should be considered to be incorporated in standard analysis of PCBs to detect potential source anomalies. Vertical profiles from soil cores suggest that the movement of PCBs in our investigated farmlands is congener specific. More attention should therefore be paid to the potential transfer of PCBs and PBDEs from urban sources to the terrestrial compartment in rural areas through wastewater irrigation.

\section{Acknowledgments}

This work was funded by National Natural Science Foundation of China (20897011, 20707033, 20677068), Chinese Academy and Sciences (KZCX1-YW-06-03), and National Basic Research Program of China (CB2009CB421605).

\section{Appendix A. Supplementary material}

Supplementary data associated with this article can be found, in the online version, at doi:10.1016/j.chemosphere.2010.07.045.

\section{References}

Alcock, R.A., Bacon, J., Bardget, R.D., Beck, A.J., Haygarth, P.M., Lee, R.G.M., Parker, C.A., Jones, K.C., 1996. Persistence and fate of polychlorinated biphenyls (PCBs) in sewage sludge-amended agricultural soils. Environ. Pollut. 93, 83-92.

Armitage, J.M., Hanson, M., Axelman, J., Cousins, I.T., 2006. Levels and vertical distribution of PCBs in agricultural and natural soils from Sweden. Sci. Total Environ. 371, 344-352.

Beck, A.J., Johnson, D.L., Jones, K.C., 1996. The form and bioavailability of non-ionic organic chemicals in sewage sludge-amended agricultural soils. Sci. Total Environ. 185, 125-149.

Bi, X., Chu, S., Meng, Q., Xu, X., 2002. Movement and retention of polychlorinated biphenyls in a paddy field of WenTai area in China. Agric. Ecosyst. Environ. 89, 241-252.

Chen, Y., Wang, C.X., Wang, Z.J., 2005. Residues and source identification of persistent organic pollutants in farmland soils irrigated by effluents from biological treatment plants. Environ. Int. 31, 778-783.

Cousins, I.T., Gevao, B., Jones, K.C., 1999. Measuring and modelling the vertical distribution of semivolatile organic compounds in soils I: PCB and PAH soil core data. Chemosphere 39, 2507-2518.
Doick, K.J., Klingelmann, E., Burauel, P., Jones, K.C., Semple, K.T., 2005. Long-term fate of polychlorinated biphenyls and polycyclic aromatic hydrocarbons in an agricultural soil. Environ. Sci. Technol. 39, 3663-3670.

During, R.-A., Gath, S., 2002. Depth distribution and bioavailability of pollutants in long-term differently tilled soils. Soil Till. Res. 66, 183-195.

Ejarrat, E., Marsh, G., Labandeira, A., Barcelo, D., 2008. Effect of sewage sludges contaminated with polybrominated diphenylethers on agricultural soils. Chemosphere 71, 1079-1086.

Gerecke, A.C., Hartmann, P.C., Heeb, N.V., Kohler, H.-P.E., Giger, W., Schmid, P., Zennegg, M., Kohler, M., 2005. Anaerobic degradation of decabromodiphenyl ether. Environ. Sci. Technol. 39, 1078-1083.

Goel, A., McConnell, L.L., Torrents, A., Scudlark, J.R., Simonich, S., 2006. Spray irrigation of treated municipal wastewater as a potential source of atmospheric PBDEs. Environ. Sci. Technol. 40, 2142-2148.

Guo, L., Zhang, B., Ke, X., Zhang, Q.H., Zheng, M.H., 2009. Levels and distributions of polychlorinated biphenyls in sewage sludge of urban wastewater treatment plants. J. Environ. Sci. 21, 468-473.

Han, X., O'Connor, J.C., Donner, E.M., Nabb, D.L., Mingioa, R.T., Snajdr, S.I., Clarke, J.J., Kaplan, A.M., 2009. Non-coplanar 2, 2', 3, 3', 4, 4', 5, 5', 6, 6'-decachlorobiphenyl (PCB 209) did not induce cytochrome P450 enzyme activities in primary cultured rat hepatocytes, was not genotoxic, and did not exhibit endocrinemodulating activities. Toxicology 255, 177-186.

Harner, T., Shoeib, M., Diamond, M.L., Stern, G., Rosenberg, B., 2004. Using passive air samplers to assess urban-rural trends for persistent organic pollutants. 1 Polychlorinated biphenyls and organochlorine pesticides. Environ. Sci. Technol. 38, 4474-4483.

Hollander, A., Baijens, I., Ragas, A., Huijbregts, M., van de Meent, D., 2007. Validation of predicted exponential concentration profiles of chemicals in soils. Environ Pollut. 147, 757-763.

Howell, N.L., Suarez, M.P., Rifai, H.S., Koenig, L., 2008. Concentrations of polychlorinated biphenyls (PCBs) in water, sediment, and aquatic biota in the Houston Ship Channel, Texas. Chemosphere 70, 593-606.

Hu, D.F., Hornbuckle, K.C., 2010. Inadvertent polychlorinated biphenyls in commercial paint pigments. Environ. Sci. Technol. 44, 2822-2827.

Krauss, M., Wilcke, W., Zech, W., 2000. Polycyclic aromatic hydrocarbons and polychlorinated biphenyls in forest soils: depth distribution as indicator of different fate. Environ. Pollut. 110, 79-88.

Matscheko, N., Tysklind, M., de Wit, C.A., Bergek, S., Andersson, R., Sellstrom, U., 2002. Application of sewage sludge to arable land-soil concentrations of polybrominated diphenyl ether and polychlorinated dibenzo-p-dioxins, dibenzofurans, and biphenyls, and their accumulation in earthworms. Environ. Toxicol. Chem. 21, 2515-2525.

Meijier, S.N., Ockenden, W.A., Sweetman, A., Breivik, K., Grimalt, J.O., Jones, K.C., 2003. Global distribution and budget of PCBs and HCB in background surface soils: implications for sources and environmental processes. Environ. Sci. Technol. 37, 667-672.

Moeckel, C., Nizzetto, L., Guardo, A.D., Steinnes, E., Freppaz, M., Filippa, G., Camporini P., Benner, J., Jones, K.C., 2008. Persistent organic pollutants in boreal and montane soil profiles: distribution, evidence of processes and implications for global cycling. Environ. Sci. Technol. 42, 8374-8380.

North, K.D., 2004. Tracking polybrominated diphenyl ether releases in a wastewater treatment plant effluent, Palo Alto, California. Environ. Sci. Technol. 38, 44844488.

Ockenden, W.A., Breivik, K., Meijier, S.N., Steinnes, E., Sweetman, A., Jones, K.C. 2003. The global re-cycling of persistent organic pollutants is strongly retarded by soils. Environ. Pollut. 121, 75-80.

Ren, N.Q., Que, M.X., Li, Y.F., Liu, Y., Wan, X.N., Xu, D.D., Sverko, E., Ma, J.M., 2007 Polychlorinated biphenyls in chinese surface soils. Environ. Sci. Technol. 41, 3871-3876.

Rodenburg, L.A., Guo, J., Du, S., Cavallo, G.J., 2010. Evidence for unique and ubiquitous environmental sources of 3, 3'-dichlorobiphenyl (PCB 11). Environ. Sci. Technol. 44, 2816-2821.

Rowe, A.A., Totten, L.A., Xie, M., Fikslin, T.J., Eisenreich, S.J., 2007. Air-water exchange of polychlorinated biphenyls in the delaware river. Environ. Sci. Technol. 41, 1152-1158.

Scott, C.A., Faruqui, N.I., Rashid-Sally, L., 2004. Wastewater use in irrigated agriculture: management challenges in developing countries. Wastewater use in irrigated agriculture: coordinating the livelihood and environmental realities. International Development Research Centre.

Sellstrom, U., de Wit, C.A., Lundgren, N., Tysklind, M., 2005. Effect of sewage-sludge application on concentrations of higher-brominated diphenyl ethers in soils and earthworms. Environ. Sci. Technol. 39, 9064-9070.

Soderstrom, G., Sellstrom, U., de Wit, C.A., Tysklind, M., 2003. Photolytic debromination of decabromodiphenyl ether (BDE 209). Environ. Sci. Technol. $38,127-132$

Song, Y.F., Wilke, B.M., Song, X.Y., Gong, P., Zhou, Q.X., Yang, G.F., 2006. Polycyclic aromatic hydrocarbons (PAHs), polychlorinated biphenyls (PCBs) and heavy metals (HMs) as well as their genotoxicity in soil after long-term wastewater irrigation. Chemosphere 65, 1859-1868.

Stockholm Convention on Persistent Organic Pollutants, <http://chm.pops.int/>.

Sun, K., Zhao, Y., Bao, B., Liu, X., Zhang, Z., Xing, B., 2009. Organochlorine pesticides and polybrominated diphenyl ethers in irrigated soils of Beijing, China: levels, inventory and fate. Chemosphere 77, 1199-1205.

ter Laak, T.L., van Eijkeren, J.C.H., Busser, F.J.M., van Leeuwen, H.P., Hermens, J.L.M., 2009. Facilitated transport of polychlorinated biphenyls and polybrominated diphenyl ethers by dissolved organic matter. Environ. Sci. Technol. 43, 1379-1385. 
Wang, Y.W., Li, X.M., Li, A., Wang, T., Zhang, Q.H., Wang, P., Fu, J.J., Jiang, G.B., 2007. Effect of municipal sewage treatment plant effluent on bioaccumulation of polychlorinated biphenyls and polybrominated diphenyl ethers in the recipient water. Environ. Sci. Technol. 41, 6026-6032.

Wilson, S.C., Duarte-Davidson, R. Jones, K.C. 1996. Screening the environmental fate of organic contaminants in sewage sludges applied to agricultural soils: 1 . The potential for downward movement to groundwater. Sci. Total Environ. 185, 45-57.
Wong, M.H., Wu, S.C., Deng, W.J., Yu, X.Z., Luo, Q., Leung, A.O.W., Wong, C.S.C., Luksemburg, W.J., Wong, A.S., 2007. Export of toxic chemicals - A review of the case of uncontrolled electronic-waste recycling. Environ. Pollut. 149, 131140.

Zou, M.Y., Yan, R., Gong, J., Mai, B.X., Zeng, E.Y., 2007. Polybrominated diphenyl ethers in watershed soils of the pearl river delta, China: occurrence, inventory, and fate. Environ. Sci. Technol. 41, 8262-8267. 